\title{
Productivity Impacts in Building Life-Cycle Cost Analysis
}

Barbara C. Lippiatt

Stephen F. Weber

Computing and Applied Mathematics Laboratory

Office of Applied Economics

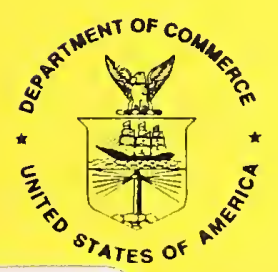

$-\mathrm{QC}$

100

.056

4762

1992

\section{spartment of Commerce}

logy Administration

al Institute of Standards and Technology sburg, MD 20899

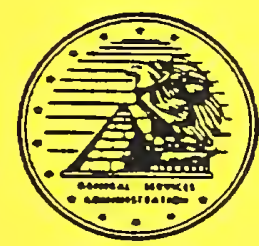

Prepared for:

U.S. General Services Administration Public Buildings Service

Office of Real Property Development Washington, DC 20405

C. 2 


\section{Productivity Impacts in Building Life-Cycle Cost Analysis}

Barbara C. Lippiatt

Stephen F. Weber

February 1992

Computing and Applied Mathematics Laboratory

Office of Applied Economics

Gaithersburg, Maryland 20899

\section{U.S. Department of Commerce}

Rockwell A. Schnabel, Acting Secretary

Technology Administration

Robert M. White, Under Secretary for Technology

National Institute of Standards and Technology

John W. Lyons, Director
Prepared for:

U.S. General Services Administration

Richard G. Austin, Administrator

Public Buildings Service

William C. Coleman, Commissioner Office of Real Property Development

Washington, D.C. 20405 



\section{Abstract}

Since employee salaries far exceed building costs, higher-priced office designs that enhance productivity may make economic sense. A method for including productivity benefits in building economic analysis could account for productivity differences among design alternatives. Two suitable economic methods are the net benefits method and the multi-attribute decision analysis method. The methods and their data requirements are described. Each is illustrated with a hypothetical case application. The methods are compared with respect to a set of evaluation criteria, including compatibility with life-cycle cost analysis, ease of use, data requirements, and form of results. Based on this evaluation, the net benefits method is recommended as most appropriate for including employee productivity in building economic analysis.

Key words: building design; building economics; building environment; building performance; lifecycle cost analysis; multi-attribute decision analysis; net benefits method; productivity measurement; white-collar productivity. 


\section{Acknowledgments}

The authors thank David Eakin and Dwain Warne of the Public Buildings Service of the U.S. General Services Administration for their support and direction of this work. The comments of NIST reviewers Harold Marshall, Sieglinde Fuller, and Arthur Rubin inspired many improvements. Jed Cohen deserves thanks for assisting in the literature search and review. 


\section{Contents}

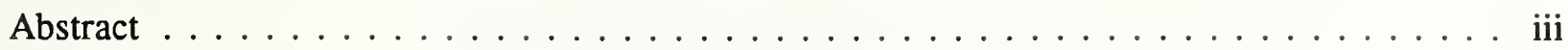

Acknowledgments $\ldots \ldots \ldots \ldots \ldots \ldots \ldots \ldots \ldots \ldots \ldots \ldots \ldots \ldots \ldots \ldots \ldots$

List of Tables $\ldots \ldots \ldots \ldots \ldots \ldots \ldots \ldots \ldots \ldots \ldots \ldots \ldots \ldots \ldots$

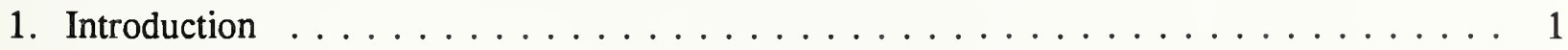

1.1 Background . . . . . . . . . . . . . . . . . . 1

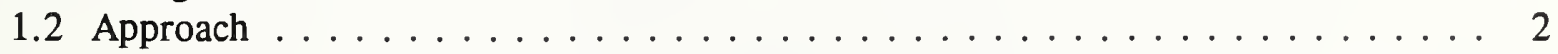

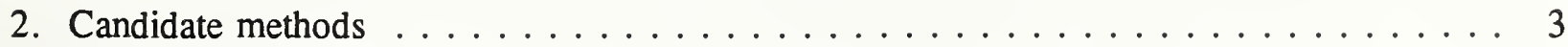

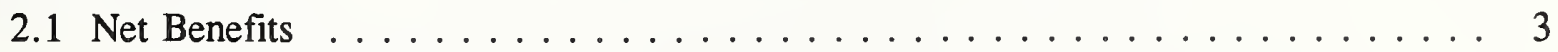

2.1 .1 The Method ......................... 3

2.1.2 Data Requirements--Productivity Impact Functions $\ldots \ldots \ldots . \ldots 4$

2.1 .3 Case Illustration . . . . . . . . . . . . . . . 6

2.2 Multi-Attribute Decision Analysis . . . . . . . . . . . . . . 9

2.2.1 The Method .......................... . . . 9

2.2.2 Data Requirements . . . . . . . . . . . . . . . 10

2.2 .3 Case Illustration . . . . . . . . . . . . . . . . . 11

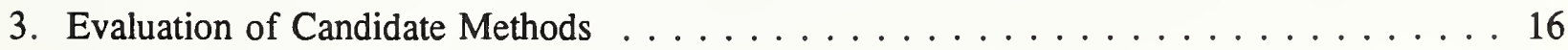

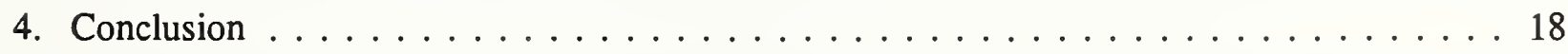

Bibliography . . . . . . . . . . . . . . . . . . . . . . 19 


\section{List of Tables}

Table 2-1. Increase in floor area and costs for alternate building design $\ldots \ldots \ldots \ldots$

Table 2-2. Hypothetical Productivity Impact Functions for floor area, by job type . . . . . 7

Table 2-3. Compute annual productivity benefits for alternate design $\ldots \ldots \ldots \ldots$

Table 2-4. Compute Net Benefits for alternate design . . . . . . . . . . . . . . . . 9

Table 2-5. Illustrative Analytic Hierarchy Process model $\ldots \ldots \ldots \ldots \ldots$

Table 2-6. Pairwise comparisons and weights for criteria $\ldots \ldots \ldots \ldots$

Table 2-7. LCC data and ratings for design alternatives $\ldots \ldots \ldots \ldots \ldots \ldots$

Table 2-8. Pairwise comparisons and ratings for productivity criteria $\ldots \ldots \ldots \ldots \ldots$

Table 2-9. Overall ratings and ranks of alternatives $\ldots \ldots \ldots \ldots \ldots \ldots$

Table 3-1. Evaluation of candidate methods . . . . . . . . . . . . . . 17 


\section{Introduction}

\subsection{Background}

Comparing the life-cycle costs of alternate office building designs has become increasingly important over the last two decades. The steep rise in energy prices encouraged serious consideration of future costs during the design process. Higher-priced, energy efficient designs were selected on the basis of their future energy cost savings. Another future cost, however, has been largely ignored in lifecycle cost (LCC) analysis--employee productivity. Building design affects productivity through ambient conditions such as noise, air quality, lighting, and temperature, and through workspace conditions such as enclosure, size, and layout. Higher-priced designs that enhance productivity may make economic sense.

Even a minor productivity gain or loss has major cost consequences. Employee salaries are by far the largest component of cost in office buildings. On an annualized, per square meter (square foot) basis, employee salaries are about 13 times building costs. ${ }^{1}$ This lopsided cost relationship justifies a 13 percent increase in construction costs for a new design that increascs productivity by only 1 percent.

But just how much an improvement in productivity is feasible? A survey of recent research on the impact of building design on productivity found a 5 to 10 percent increase in productivity to be feasible. Given the U.S. annual expenditure of $\$ 1$ trillion for white-collar salaries, a 5 percent productivity increase translates into $\$ 50$ billion per year. ${ }^{2}$

Current literature reveals heightened awareness of the importance of productivity impacts of building design. ${ }^{3}$ Yet little progress has been made toward systematically including productivity impacts in

${ }^{1}$ Brill, M. et al., Using Office Design to Increase Productivity, Workplace Design and Productivity, Inc., Buffalo, NY, 1984, pp. 30-31. Building costs include costs of construction, operation, maintenance, furniture, and equipment.

${ }^{2}$ Ward, R., "Office Building Systems Performance and Functional Use Costs," in Building Economics, edited by D. O. Pedersen and J. Soderberg, International Council for Building Research Studies and Documentation, Copenhagen, 1987, p. 115.

${ }^{3}$ See, for example, Osgood, R. T., "Measuring the Bottom Line Impact of Design and Facility Management on Office Workers' Satisfaction and Productivity," in IFMA '89: Excellence in Facility Management, Seattle, WA, 1989; Ruck, N. C. (ed.), Building Design and Human Performance, Van Nostrand Reinhold, New York, NY, 1989; Steelcase, Inc., Office Environment Index: 1989 Detailed Findings, New York, 1989; and Woods, J. E., "Cost Avoidance and Productivity in Owning and Operating Buildings," Occupational Medicine: State of the Art Reviews, Vol. 4, No. 4, OctoberDecember 1989, pp. 753-770. 
building economic analysis. Without explicit treatment of productivity, it is difficult to justify higher-priced designs based on productivity improvements.

\subsection{Approach}

The U.S. General Services Administration (GSA) has well-defined criteria for performing LCC analysis in the Handbook Facilities Standards for the Public Buildings Service. The Handbook has no provision, however, for including productivity losses or gains that might accrue from choosing alternate building designs or components. The first step toward formal recognition of productivity impacts in GSA's building design decisions is developing an economic method for including productivity impacts in building LCC analysis.

A literature review identified two suitable economic methods. ${ }^{4}$ The candidate methods are described and their data requirements specified. Each is illustrated by means of a hypothetical case application. A consistent set of criteria for evaluating the alternate methods is described. Each method is evaluated against each criterion. The results are organized in a concise format that facilitates comparing the methods. Based on this evaluation, the method most appropriate for including employee productivity in building LCC analysis is recommended.

${ }^{4}$ For a description of the literature review, see Bibliography. 


\section{Candidate methods}

A candidate method must consider all relevant costs and benefits from a project investment over its life. Relevant costs include costs of initial investment, replacements, operations (including energy use), maintenance, and repair. Relevant benefits include productivity improvements. The method must combine costs and benefits into a single measure of economic worth for comparison with alternate projects. The project with the best relative worth may then be selected.

LCC analysis assumes that all design alternatives under consideration offer an acceptable level of overall building performance over the study period. The alternatives are judged only on the basis of cost effectiveness. A project alternative is cost effective when its costs are lower than competing projects assumed to have equal performance, or benefits. Differences in benefits above the minimum acceptable level tend to be ignored. Two candidate methods for accounting for these typically ignored benefits, such as productivity improvements, are described below.

\subsection{Net Benefits}

\subsubsection{The Method ${ }^{5}$}

The Net Benefits (NB) method expands LCC analysis by comparing projects that differ not only in costs, but in benefits as well. Because it permits alternatives to compete on costs and benefits, the NB method measures economic efficiency rather than cost effectiveness. In the private sector, economic efficiency is synonymous with maximum profits, in the public sector, with maximum NB.

The NB method is a widely used, straightforward tool of investment analysis. It may be used to select the most economically efficient from among multiple investment alternatives. It is an incremental economic evaluation technique--the NB measure is computed not by evaluating each project alternative separately, but by evaluating each relative to the base case alternative. The base case alternative is usually the lowest investment cost alternative; in some cases the zero investment cost alternative of doing nothing. For this application, the base case alternative will be that design which just meets minimum design requirements.

The method requires that project alternatives be compared over the same study period. As with any economic evaluation method, it involves discounting costs and benefits over the study period to an equivalent time basis so that they may be combined and compared. When the equivalent time basis is today, the amounts are known as present values. NB is calculated as present-value benefits less present-value costs as follows:

${ }^{5}$ This subsection is based on Ruegg, R. T. and Marshall, H. E., "Net Benefits (NB) and Net Savings (NS)," Chapter 3 of Building Economics: Theory and Practice, Van Nostrand Reinhold, New York, NY, 1990. 


$$
\mathrm{NB}_{\mathrm{A} 2: \mathrm{A} 1}=\sum_{t=0}^{N} \frac{B_{t}-C_{t}}{(1+d)^{t}}
$$

$$
\begin{aligned}
\text { where } & \\
\mathrm{NB}_{\mathrm{A} 2 \mathrm{~A} 1 \mathrm{~A}}= & \text { benefits less costs, in present value dollars, of project alternative } \mathrm{A} 2 \text { relative } \\
& \text { to base case alternative } \mathrm{A} 1, \\
\mathrm{~B}_{\mathrm{t}}= & \text { benefits (e.g., productivity gains) for alternative } \mathrm{A} 2 \text { less benefits (if any) for } \\
& \text { alternative } \mathrm{A} 1 \text { in time period } \mathrm{t} \\
\mathrm{C}_{\mathrm{t}}= & \text { costs for alternative } \mathrm{A} 2 \text { less costs for alternative } \mathrm{A} 1 \text { in time period } \mathrm{t}, \\
\mathrm{d}= & \text { discount rate reflecting investor's minimum acceptable rate of return, and } \\
\mathrm{N}= & \text { number of years in study period. }
\end{aligned}
$$

NB is computed for each project alternative $A_{i}(i \neq 1)$ relative to the base case alternative $A_{1}$. If NB is positive, project $A_{i}$ is economic, and if $N B$ is negative, uneconomic. Uneconomic projects are ruled out. The decision rule is to select the project with the highest NB, or if none has positive NB, to select the base case alternative.

It is useful to perform breakeven analysis for key input values, such as productivity impacts, to determine the minimum or maximum values they can reach and still yield an economic project. Applied to the NB method, the breakeven value for productivity benefits is the minimum value at which NB is zero. A breakeven value is useful in indicating the order of magnitude of required productivity benefits. Breakeven analysis provides a practical screening tool indicating when more detailed analysis is warranted.

Woods has proposed the following technique for applying breakeven analysis to productivity impacts. ${ }^{6}$ For any design alternative, the breakeven value is the gain (loss) in employee productivity that would be required (allowed) before the alternative would be considered economic (uneconomic). For example, consider a design specifying offices with 25 percent more floor area than minimum space requirements. Suppose increased costs for this productivity-enhancing design were equivalent to one percent of the annual wage and salary bill. The breakeven value for productivity benefits then, the value for which NB is zero, is one percent of salaries. If greater floor area enhances productivity and results in increased performance of employees equivalent to more than one percent of their salaries, the productivity-enhancing design is economic.

\subsubsection{Data Requirements--Productivity Impact Functions}

The NB method needs, as input, monetary measures of productivity benefits. A system for developing monetized productivity measures, the Productivity Impact Function (PIF) system, was developed by the authors and is described below.

${ }^{6}$ Woods, J. E., "Cost Avoidance and Productivity in Owning and Operating Buildings," pp. 760762. 
The PIF system measures cause-and-effect relationships between building design and productivity. In other words, the system measures the degree to which changes in discrete attributes of the physical office environment affect worker performance. It consists of a set of functions, or PIFs. Each PIF maps changes in a particular design feature to changes in productivity. Since the nature of job activity influences whether and to what extent a design feature affects productivity, separate functions are derived for each job type. Each PIF is unique, then, to a specific combination of design feature and job type. For example, there may be a series of three PIFs for the single design feature floor area--one PIF for clerical workers, one for professional/technical workers, and one for managerial workers.

For a particular design decision, the PIF system works as follows:

(1) Identify job types and design features relevant to the design alternatives under consideration.

(2) For each relevant design feature/job type combination, apply the corresponding PIF. Each PIF needs as input the "level" of improvement in the design feature for the design alternative (e.g., extra amount of floor area, or added number and height of enclosed sides for clerical workers). The PIF yields as output the resulting annual productivity benefits for that improvement.

(3) Sum productivity benefits for all relevant PIFs for an estimate of annual productivity benefits unique to that design alternative. Use this sum as the value for annual benefits for the design alternative, $B_{t}$, in computing NB.

Supporting data relating building design to productivity are required to develop and implement the PIF system. An example of data that could support the PIF system is illustrated by the 1984 study conducted by the Buffalo Organization for Social and Technological Innovation (BOSTI). ${ }^{7}$ BOSTI undertook a five-year, $\$ 750,000$ research program to quantify design impacts on office productivity. Numerous corporations and government agencies supported the study. It involved some 6000 employees in about 70 organizations. It represents the largest database of its kind in the world.

The BOSTI results indicate that 11 office features significantly affect productivity. Examples of these features are noise, temperature fluctuation, air quality, glare, enclosure, and furniture. Productivity gains and losses arising from improvements and declines in these features were assessed and monetized. Separate estimates were derived for each of three broad job types: managerial, professional/technical, and clerical.

The BOSTI study did not publish productivity impacts for specific levels of change in office features. A change was defined as either an improvement or a decline. However, the raw data are available from the BOSTI study to develop productivity measures for specific changes in office features. The validity of the raw data should first be assessed. Statistical techniques may be used to assess

${ }^{7}$ Brill, et al., Using Office Design to Increase Productivity. 
completeness, representability, and reliability. If the evaluation is positive, PIFs may be developed by conducting regression analysis on the BOSTI data.

\subsubsection{Case Illustration}

Consider two alternate office designs, both intended for 1300 managerial, professional/technical, and clerical workers. The base design has four floors with $9290 \mathrm{~m}^{2}\left(100,000 \mathrm{ft}^{2}\right)$ of floor area allocated for offices. Workers are assigned floor area according to minimum design requirements. Construction costs total $\$ 20$ million. The alternate design has five floors and $11,613 \mathrm{~m}^{2}(125,000$ $\mathrm{ft}^{2}$ ) designated for offices. Each worker is allocated an additional 25 percent in floor area. Construction costs are $\$ 25$ million. Future costs for the alternate design (operations, maintenance, repair, and replacement costs) are expected to be $\$ 20,000$ higher annually. Table $2-1$ itemizes the major differences between the two designs.

The base design clearly costs less than the alternative. Its construction and future costs are both lower than for the alternate design. Assuming the two designs offer equal benefits, life-cycle cost analysis would obviously favor the base design.

But do the competing designs really offer equal benefits? Increased floor area may lead to better job performance and satisfaction. Contributing factors may include increased status and more room for electronic equipment and private meetings. Further, these contributing factors may affect productivity differently depending on job type.

The productivity impact of floor area, specific to job type, might be measured by PIFs such as those listed in table 2-2. Productivity is hypothetically expressed as a linear function of floor area. Each PIF measures the change in annual productivity attributable to floor area, in terms of dollars per worker.

Does the productivity benefit from the increased floor area of the alternate design compensate for its increased construction and future costs? Let us compute NB for the alternate design using equation (1). To do so, we need the value for $B_{t}$, or net productivity benefits for the alternate design in each time period. This value is derived in table 2-3. Column (1) gives the number of workers of each job type, and columns (2) and (4) the office floor area for the base and alternate designs. Columns (3) and (5) are derived by applying the floor area PIFs of table 2-2. Note that the base design offers no productivity benefits (column (3)), as it just meets minimum design requirements. The alternate design, however, does have productivity benefits. In fact, productivity benefits average almost 2 percent of salaries (assuming average annual salaries of $\$ 55,000$ for managers, $\$ 45,000$ for professional/technical, and $\$ 25,000$ for clerical). Productivity benefits are aggregated and summed in column (6). The resulting value for $\mathrm{B}_{\mathrm{t}}$ is about $\$ 1.1$ million/year in productivity benefits for the alternate design. 
Table 2-1. Increase in floor area and costs for alternate building design

Description

floor area

construction cost $\left(\mathrm{C}_{\mathrm{o}}\right)$

future costs $\left(\mathrm{C}_{\mathrm{t}, \neq 0}\right)$
Increase

$+2323 \mathrm{~m}^{2}\left(+25,000 \mathrm{ft}^{2}\right)$

$+\$ 5$ million

$+\$ 20,000 / y r$

Table 2-2. Hypothetical Productivity Impact Functions for floor area, by job type*

Job Type

manager

professional/technical

clerical
PIF for floor area

$\$ /$ yr $/$ person $=\left(296 \times \mathrm{m}^{2} /\right.$ office $)-3161$

[\$/yr/person $=\left(27.6 \times \mathrm{ft}^{2} /\right.$ office $\left.)-3174\right]$

$\$ /$ yr/person $=\left(487 \times \mathrm{m}^{2} /\right.$ office $)-3711$

[\$/yr/person $=\left(45.2 \times \mathrm{ft}^{2} /\right.$ office $\left.)-3706\right]$

$\$ /$ yr/person $=\left(485 \times \mathrm{m}^{2} /\right.$ office $)-1935$

[\$/yr/person $=\left(45.5 \times \mathrm{ft}^{2} /\right.$ office $\left.)-1957\right]$

These hypothetical PIFs are assumed to apply to a limited range of office floor area. Productivity impact likely reaches limiting values beyond a certain range. 


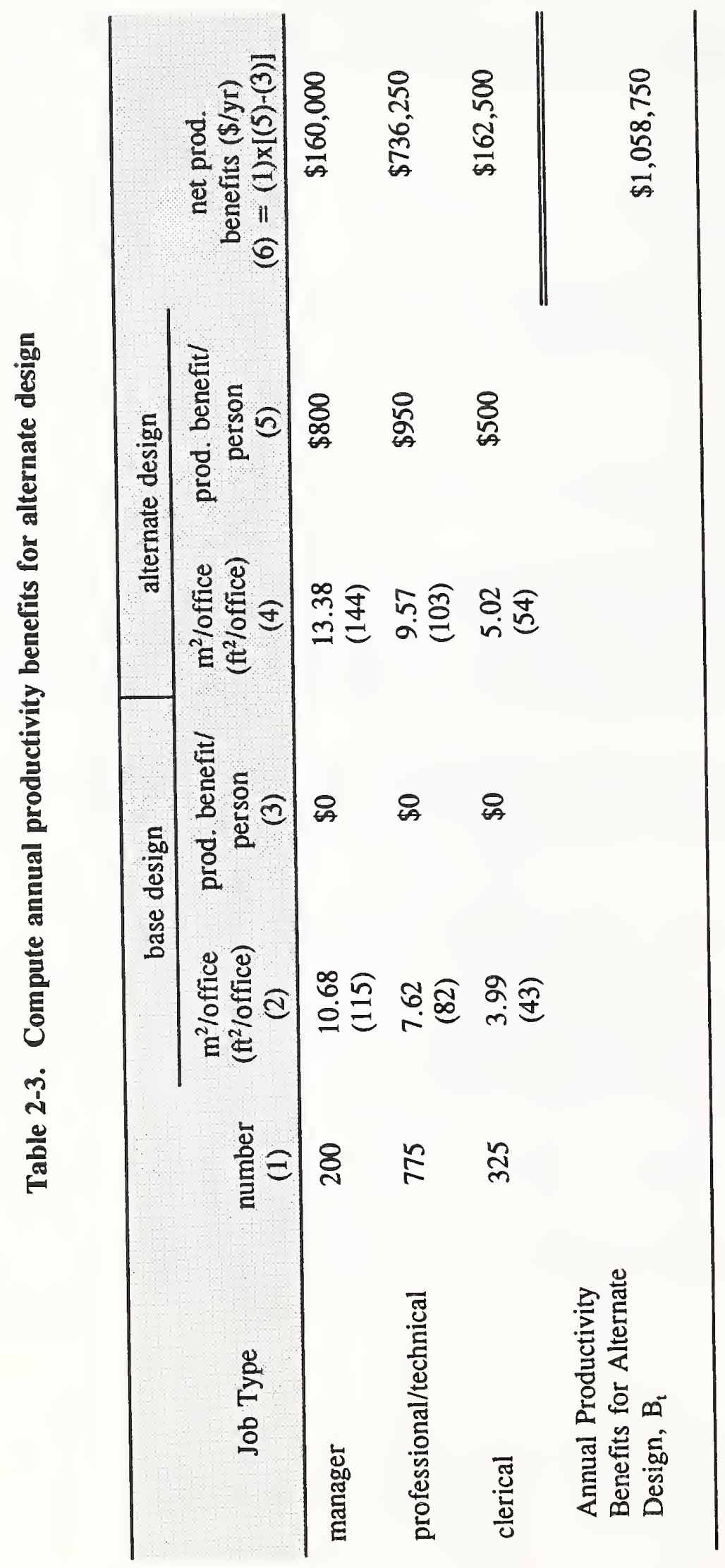


Table 2-4. Compute Net Benefits for alternate design

\begin{tabular}{ccccc}
\hline $\begin{array}{c}\mathrm{C}_{\mathrm{o}} \\
(1)\end{array}$ & $\begin{array}{c}\mathrm{C}_{\mathrm{t}, \neq 00} \\
(2)\end{array}$ & $\begin{array}{c}\mathrm{B}_{\mathrm{t}, \mathrm{t} \neq 0} \\
(3)\end{array}$ & $\begin{array}{c}\mathrm{B}_{\mathrm{t}}-\mathrm{C}_{\mathrm{t}} \\
(4)=(3)-(2)\end{array}$ & $\begin{array}{c}\mathrm{NB}_{\text {Att:Base }} \\
(5)\end{array}$ \\
\hline \multirow{2}{*}{$\$ 5$ million } & $\$ 20,000$ & $\$ 1,058,750$ & $\$ 1,038,750$ & $\$ 4.4$ million \\
\hline
\end{tabular}

"Refer to equation (1) for NB formula. Assumptions: $N=25$ years, $d=10$ percent, and wages and energy prices escalate at the general price inflation rate.

Now we can compute NB. Input data are consolidated in columns (1) through (3) of table 2-4. Using equation (1), we find the alternate design to have net benefits of $\$ 4.4$ million, as shown in column (5). Its increased floor area overwhelmingly pays for itself through productivity benefits. The alternate design is clearly the economically efficient choice. In this case, a 2 percent productivity increase justifies a 25 percent increase in construction costs.

\subsection{Multi-Attribute Decision Analysis}

\subsubsection{The Method}

This section describes the other candidate method for incorporating employee productivity into LCC analysis. It is called Multi-Attribute Decision Analysis (MADA) because it permits more than one performance attribute or criterion to be considered in a decision, even if the criteria are not measured in comparable units. ${ }^{8}$ For example, MADA can account simultaneously for both traditional LCC measures denominated in dollars, and nonmonetary measures of productivity impact. Productivity impact may be expressed in physical dimensions, such as square meters (square feet) or decibels of sound energy, or even be based solely on informed judgments. This approach provides an alternative to developing monetary measures of productivity impact with the PIF system, as required by the NB method.

${ }^{8}$ For more information on multi-criteria decision methods, see Zeleny, M., Multiple Criteria Decision Making, McGraw-Hill, Inc., New York, NY, 1982; Goicoechea et al., Multiobjective Decision Analysis with Engineering and Business Applications, John Wiley and Sons, New York, NY, 1982; and Canada, J. R. and Sullivan, W. G., Economic and Multiattribute Evaluation of Advanced Manufacturing Systems, Prentice Hall, Englewood Cliffs, NJ, 1989. 
The illustration in this section focuses on one particular type of MADA, the Analytic Hierarchy Process (AHP), which has recently gained in popularity and been applied to a wide variety of decisions. ${ }^{9}$ The AHP applies a formal structure and modern mathematical techniques to assure consistency when decisions require evaluations based on several diverse criteria. It facilitates comparisons between "apples and oranges" by providing a scoring system based on a common denominator.

The AHP structures a complex decision into a hierarchy with the decision criteria at the top and the alternatives to be evaluated at the bottom. The decision criteria may be grouped into categories to form the top two levels of the hierarchy. Decision makers then establish relative weights among the criteria through a sequential process of pairwise comparisons. Pairwise comparisons are based on judgments about the relative importance between any two criteria. AHP then uses a mathematical technique based on eigenvectors to derive the relative weights from the pairwise comparison data.

Decision makers establish relative performance scores for each alternative with respect to each criterion. The relative weights are combined with the performance scores to derive a single overall rating for each decision alternative.

A major strength of the AHP is that it does not require perfect consistency among the pairwise comparison judgments. For example, $\mathrm{A}$ need not be four times as good as $\mathrm{C}$ just because $\mathrm{A}$ is twice as good as B and B is twice as good as C. ${ }^{10}$ The AHP is robust enough to tolerate a certain degree of inconsistency among judgments. The method even provides an explicit measure on inconsistency to inform decision makers whether judgments need to be reviewed.

\subsubsection{Data Requirements}

To develop the hierarchical structure of the decision model, the AHP requires specification of all criteria relevant to a decision and all alternatives to be considered. The numeric data needed to implement the decision model serve two purposes: (1) to weight criteria; and (2) to rate alternatives.

To weight criteria, decision makers must answer questions like the following for each pair of criteria:

${ }^{9}$ The AHP technique was developed in the 1970's by Thomas L. Saaty at the Wharton School of the University of Pennsylvania. For more information on the AHP, see Saaty, T. L., The Analytic Hierarchy Process: Planning, Priority Setting, Resource Allocation, McGraw-Hill, Inc., New York, NY, 1988; and Gass, S. I., "The Analytic Hierarchy Process," Chapter 24 of Decision Making, Models, and Algorithms, John Wiley and Sons, New York, NY, 1985, pp. 355-397. For illustrative applications of the AHP to manufacturing investment decisions, see Weber, S. F. et al., AutoMan 2.0: Decision Support Software for Automated Manufacturing Investments -- User Manual, NISTIR 4543, National Institute of Standards and Technology, Gaithersburg, MD, 1991.

\footnotetext{
${ }^{10}$ In technical terms, this means that the user is not forced to preserve cardinal transitivity among comparisons.
} 


\section{Criterion $A$ is how many times as important as Criterion $B$ ?}

Note that the type of data called for here is not ordinal but cardinal. It is not sufficient to answer simply whether A is preferred to B (ordinal ranking), but rather by how much A is preferred to B (cardinal preference). Thus, the data must be in the form of a scalar number, such as 1.5 , which would indicate that Criterion $\mathrm{A}$ is one and one half times as important as Criterion $\mathrm{B}$.

For each group of $n$ criteria to be weighted, there are $n x n$ theoretically possible comparisons to be made. Because of the two AHP axioms of reflexivity and reciprocity, however, only $n(n-1) / 2$ distinct comparison judgments are needed. The reflexivity axiom assures that Criterion $\mathrm{A}$ is of equal importance to itself (i.e., the data value of 1 is automatically entered). The reciprocity axiom assures that if Criterion $\mathrm{A}$ is $x$ times as important as Criterion $\mathrm{B}$, then Criterion $\mathrm{B}$ must be $1 / x$ times as important as Criterion A.

The data needed to rate alternatives depend on the nature of the criteria being used and consist of two basic types: pairwise comparison data and proportional data. Pairwise comparison data are similar to the data needed for weighting criteria, except the query posed for each comparison becomes:

"With respect to this criterion, Alternative $A$ is how many times as desirable as Alternative $B$ ?"

Pairwise comparison data must be used to rate alternatives whenever no reliable data exist for the criterion that are directly or inversely proportional to the desirability of alternatives. If proportional data are available for a criterion, they may be used to rate alternatives directly. For example, floor area data are directly proportional if 200 square meters ( 2153 square feet) of area are judged to be twice as desirable as 100 square meters (1076 square feet). Energy consumption data is inversely proportional if 3 million kilojoules per square meter per year $(264,000$ BTU per square foot per year) is judged half as desirable, or twice as bad or costly, as 1.5 million $(132,000)$. A similar inverse relationship would hold for other cost criteria. For some criteria, raw data that is not immediately proportional to desirability may be made so through a mathematical transformation. For example, data on a criterion related to noise or sound is likely to be in a logarithmic form. It can be transformed into a proportional rating scale by means of an exponential function. Since performance data must be proportional to desirability, the pairwise comparison method must be used for criteria with negative and zero values.

\subsubsection{Case Illustration}

Step 1 of AHP defines the decision model by establishing the performance criteria on which to base the decision and by specifying the design alternatives. Suppose a project manager is considering three design alternatives for a building project. The manager establishes the six relevant performance criteria for this decision: initial cost, operation and maintenance cost, energy cost, lighting effectiveness, air quality, and quiet. The first three of these are grouped as LCC criteria and the last three as productivity criteria. The hierarchy for this decision model is shown in table 2-5. 
Table 2-5. Illustrative Analytic Hierarchy Process model

\begin{tabular}{||l|l|}
\hline \multicolumn{2}{|c|}{ CRITERIA } \\
\hline LCC & \multicolumn{1}{|c|}{ Productivity } \\
\hline Initial Cost & Lighting Effectiveness \\
\hline Operation \& Maintenance Cost & Air Quality \\
\hline Energy Cost & Quiet \\
\hline \hline \multicolumn{2}{|c|}{ ALTERNATIVES } \\
\hline Design 1 Design 2 Design 3 \\
\hline
\end{tabular}

Step 2 of the AHP helps decision makers establish the relative importance weights for each criterion. The pairwise comparison procedure is used to first determine the importance of each of the two categories, LCC and productivity. For only two elements, the procedure is simple, requiring only a single comparison. Suppose the decision maker judges that the LCC criteria are twice as important as the productivity criteria. The AHP method computes weights as 0.667 for LCC and 0.333 for productivity. The decision maker then goes on to set the pairwise comparison values within each category of criteria. Hypothetical pairwise comparison values are shown in table 2-6. For example, initial cost is judged to be 1.2 times as important as energy cost, and lighting effectiveness 1.6 times as important as quiet. The relative weights computed from the pairwise comparison values are also shown.

Step 3 of the AHP involves rating the design alternatives with respect to each criterion. For the LCC criteria, the decision maker can use the LCC dollar amounts as the basis of the rating. The AHP method then normalizes the vector of the reciprocals of the LCC dollar amounts of all the design alternatives. That is, each reciprocal is divided by the sum of the reciprocals. This makes the ratings inversely proportional to the LCC dollar amounts. The rationale for using reciprocals is best seen by example. A design that costs half as much is twice as desirable, since two can be built for the price of one. Of course, if the LCC dollar amounts refer to revenue or rent, reciprocals would not be taken and the ratings would equal the LCC dollar amounts divided by the sum of the LCC dollar amounts. Table 2-7 shows the dollar amounts for all three LCC criteria and all three designs as well as the resulting ratings based on normalizing the reciprocals. 
Table 2-6. Pairwise comparisons and weights for criteria

\begin{tabular}{lccc}
\hline & \multicolumn{3}{c}{ LCC Criteria } \\
& Initial Cost & O\&M Cost & Energy Cost \\
\hline Initial Cost & 1.000 & 1.400 & 1.200 \\
O\&M Cost & & 1.000 & 0.800 \\
Energy Cost & & & 1.000 \\
Computed Weights & 0.392 & 0.274 & 0.334 \\
\hline \hline & & Productivity Criteria & \\
& Lighting Eff. & Air Quality & Quiet \\
\hline Lighting Eff. & 1.000 & 2.000 & 1.600 \\
Air Quality & & 1.000 & 0.800 \\
Quiet & & & 1.000 \\
Computed Weights & 0.471 & 0.235 & 0.294 \\
& & & \\
\hline
\end{tabular}

Table 2-7. LCC data and ratings for design alternatives

\begin{tabular}{lccccccc}
\hline & \multicolumn{2}{c|}{ Initial Cost } & \multicolumn{2}{c|}{ O\&M Cost } & \multicolumn{2}{c}{ Energy Cost } \\
\hline & LCC $(\$)$ & Rating & LCC $(\$)$ & Rating & LCC $(\$)$ & Rating \\
\hline Design 1 & $2,000,000$ & 0.336 & 350,000 & 0.244 & 900,000 & 0.272 \\
Design 2 & $2,500,000$ & 0.269 & 238,500 & 0.358 & 700,000 & 0.350 \\
Design 3 & $1,700,000$ & 0.395 & 215,000 & 0.397 & 650,000 & 0.377 \\
\hline
\end{tabular}

If proportional data are not available for the productivity criteria, the pairwise comparison method is used to rate the design alternatives, as discussed in Section 2.2.2. Hypothetical pairwise comparison values and the resulting computed ratings of the design alternatives are shown for the three productivity criteria in table $2-8$. 
Table 2-8. Pairwise comparisons and ratings for productivity criteria

\begin{tabular}{lccc}
\hline & & Lighting Effectiveness & \\
& Design 1 & Design 2 & Design 3 \\
\hline Design 1 & 1.000 & 1.200 & 0.800 \\
Design 2 & & 1.000 & 0.600 \\
Design 3 & & 1.000 \\
Computed Ratings & 0.323 & 0.260 & 0.418 \\
\hline \hline & & Air Quality & \\
& Design 1 & Design 2 & Design 3 \\
\hline Design 1 & 1.000 & 2.000 & 1.000 \\
Design 2 & & 1.000 & 0.500 \\
Design 3 & & 1.000 \\
Computed Ratings & 0.400 & 0.200 & 0.400 \\
\hline \hline & & Quiet & \\
& & Design 2 & Design 3 \\
\hline Design 1 & & 1.500 & 0.750 \\
Design 2 & & 1.000 & 0.500 \\
Design 3 & 1.000 & 0.222 & 1.000 \\
Computed Ratings & 0.333 & & 0.444 \\
\hline
\end{tabular}

Step 4 of the AHP involves computing the overall ratings and ranking the design alternatives accordingly. This is accomplished by summing the products of the weights times the ratings for each alternative. For this case illustration, table 2-9 shows the overall ratings and the rank order of preference of the three alternative designs. 
Table 2-9. Overall ratings and ranks of alternatives

\begin{tabular}{ccc}
\hline Rank & Alternative & Rating \\
\hline 1 & Design 3 & 0.400 \\
2 & Design 1 & 0.308 \\
3 & Design 2 & 0.292 \\
\hline
\end{tabular}

In this case illustration Design 3 turns out to have the highest overall rating by a relatively significant margin and so should be selected. If the overall ratings are very close, however, it is advisable to reconsider the pairwise comparison values to test how the final ranking might be affected.

AHP decision models that take worker productivity into account can be easily implemented with user-friendly software that guides the decision maker systematically through each step of the process. Such software can facilitate model development, data entry, consistency of judgment, and mathematical computations. The user needs no computer or mathematical expertise to build and exercise the decision model, and the results are presented both graphically and numerically. Software can even automate sensitivity analysis to permit decision makers to test the robustness of the results. ${ }^{11}$

${ }^{11}$ An example of software that facilitates implementation of the AHP and includes graphical sensitivity analysis is available in Weber et al., AutoMan 2.0. 


\section{Evaluation of Candidate Methods}

The NB and MADA methods offer two approaches to including productivity impacts in building LCC analysis. To identify which method is most appropriate, they are evaluated against the following criteria: compatibility with LCC analysis, ease of use, data requirements, and form of results.

Compatibility with LCC Analysis. The NB and MADA methods are both compatible with LCC analysis, but in different ways. The NB method essentially expands the LCC model by adding another element, benefits, to the equation. Rather than computing LCC's present-value costs, NB computes present-value benefits net of costs. The MADA method, on the other hand, includes the LCC model as one component of a larger model. The larger model is a structured framework for integrating monetary data, such as LCC, with non-monetary data, such as productivity benefits (assuming PIFs are not available). Neither method replaces or excludes any elements of the LCC model. They are both easily integrated with LCC procedures, such as those currently followed by GSA.

Ease of Use. The NB method is more straightforward and better established than the MADA method. First, the NB method is standardized and the MADA method is not. ${ }^{12}$ Standardization helps ensure accurate and consistent formulation and application. It also encourages widespread acceptance and use, as is the case with the NB method. Second, the NB method is far less computationally complex. The NB formula requires little more than simple arithmetic. The analyst can clearly understand the meaning and derivation of the NB measure. In fact, to further simplify computation, discount factor tables and software are readily available. ${ }^{13}$ The MADA method, however, requires extensive use of matrix algebra. Computer support is a must. The analyst may perceive the derivation of the MADA measure of worth as a "black box."

Data Requirements. Data requirements for the NB method are rigid, and for the MADA method, flexible. The NB method's demands for data are very specific--it requires monetary data exclusively. Typically, relevant benefits that cannot be monetized are either ignored or assumed away. In contrast, the MADA method's demands for data are minimal--it accepts a wide range of data types, including data that rely on informed judgment. This permits inclusion of more benefits in the analysis. This feature of the MADA method is its principal strength. Note, however, that at the same time it introduces an element of judgment in the analysis.

Form of Results. The NB method yields a more meaningful measure of economic worth. It gives the expected return on the extra investment required by the alternate project. The MADA method,

${ }^{12}$ The NB standard is published in "Standard Practice for Measuring Net Benefits for Investments in Buildings and Building Systems (E 1074-91)," 1991 Annual Book of ASTM Standards, Vol. 04.07, American Society for Testing and Materials, Philadelphia, PA, 1991, pp. 876-878.

${ }^{13}$ See American Society for Testing and Materials, Discount Factor Tables, Adjunct E917, Philadelphia, PA, 1990; and Petersen, S. R., DISCOUNT--A Program for Discounting Computations in Life-Cycle Cost Analyses, NISTIR 4513, National Institute of Standards and Technology, Gaithersburg, MD, 1991. 
on the other hand, gives an overall "score," a dimensionless measure of relative worth. Dollars are a more useful measure of worth. They better indicate how much better one alternative is over another. It is easier to compare two project alternatives with $\$ 100,000$ and $\$ 10,000$ returns than two with 0.521 and 0.480 overall ratings. Further, the NB measure shows profitability, whereas the MADA measure simply shows relative rank.

Table 3-1 summarizes the evaluation results. The two methods are equally compatible with LCC analysis as currently defined in the GSA Handbook. Data requirements at present favor the flexible MADA method. The NB method, however, is easier to use and its results are more meaningful. Further, its data requirements can be satisfied by developing the PIF system. This requires further work, but it may be more satisfactory in the long run as it avoids the element of judgment introduced by the MADA method. Consequently, the NB method is recommended for including productivity impacts in building LCC analysis at the GSA. The method directly supports LCC analysis and is well established, widely used, and straightforward in application.

Table 3-1. Evaluation of candidate methods

$\begin{array}{lll}\text { Evaluation Criteria } & \text { NB } & \text { MADA }\end{array}$

$\begin{array}{ccc}\text { LCC Compatibility } & \text { compatible } & \text { compatible } \\ \text { Ease of Use } & \text { simple } & \text { complex } \\ \text { Data Requirements } & \text { rigid } & \text { flexible } \\ \text { Form of Results } & \text { monetary } & \text { dimensionless }\end{array}$




\section{Conclusion}

LCC analysis does not account for the productivity benefits of new building technologies. It judges project alternatives on cost effectiveness alone. Productivity benefits can be accounted for by expanding the LCC model (NB) or by using LCC as part of another model (MADA). The NB method appears the most practical and efficient solution to systematically including productivity benefits in LCC analysis.

The NB method needs monetary measures of productivity benefits. The Productivity Impact Function (PIF) system is a valid system for developing monetary productivity measures. PIFs specify the critical cause-and-effect relationships between design and productivity. A promising database exists for developing PIFs. If the database passes statistical tests, the PIF system should be developed using this database to fully implement the NB method.

Higher-priced designs that enhance productivity may make more economic sense. Yet without an economic method for systematically including productivity benefits in building LCC analysis, these designs cannot be justified. The NB method offers a practical solution to this problem. 


\section{Bibliography}

Through a computerized search and personal contacts, literature related to including productivity impacts in building LCC analysis was found. The computerized search covered engineering, architectural, economic, medical, and governmental databases from 1980 to 1991. A key-word strategy was devised to assure comprehensive coverage of potentially valuable studies in this area.

The literature covers many topics, including white-collar productivity measurement, building performance, "sick" buildings, and the productivity impacts of specific design features. No published studies were found that include productivity impacts in building LCC analysis. However, there are studies documenting linkages along the chain of causality. For example, engineering studies have documented linkages between specific building design changes and the indoor environment, medical studies have documented linkages between indoor environmental conditions and office worker illness, and economic studies link office worker illness to productivity.

American Productivity and Quality Center, Measuring White Collar Work (Houston, TX, 1988).

American Productivity Center, White-Collar Productivity: The National Challenge (Houston, TX, 1982).

American Society for Testing and Materials, Discount Factor Tables, Adjunct E917 (Philadelphia, PA, 1990).

Barnaby, J.F. "Lighting for Productivity Gains," Lighting Design and Application, Vol. 10, No. 2, February 1980 , pp. 20-28.

Berglind, Bradford L. and Scales, Charles D, "White Collar Productivity: Seeing Through the Camouflage," Management Review, June 1987, pp. 41-46.

Brill, Michael et al., Using Office Design to Increase Productivity (Buffalo, NY: Workplace Design and Productivity, Inc., 1984).

Burge, Sherwood et al., "Sick Building Syndrome: A Study of 4373 Office Workers," Ann Occup Hyg, Vol.311, No. 4A, 1987, pp. 493-504.

Canada, John R. and Sullivan, William G., Economic and Multiattribute Evaluation of Advanced Manufacturing Systems (Englewood Cliffs, NJ: Prentice Hall, 1989).

Clear, Robert and Berman, Samuel, "Relating Productivity to Visibility and Lighting," presented at Public Works Canada Symposium "The Integration of Visual Performance Criteria into the Illumination Design Process," Ottawa, Ontario, January 25-27, 1982. 
Cone, James E. and Hodgson, Michael J. (eds.), Occupational Medicine: State of the Art Reviews. Problem Buildings: Building-Associated Illness and the Sick Building Syndrome, Vol. 4, No. 4, October-December 1989.

Dolden, Mary E. and Ward, Robertson, Jr. (eds.), The Architectural Research Centers Consortium Workshop on The Impact of the Work Environment on Productivity, Washington, DC, April 17-19, 1985.

Dorgan, C.E., "Advanced Control Concepts Related to Comfort, Indoor Air Quality, and Productivity," IAQ '88: Engineering Solutions to Indoor Air Problems, Atlanta, GA, 1988.

Frazelle, Ed and Smith, Clarence, "Productivity Improvement Through Office-Space Planning," National Productivity Review, Vol. 4, No. 3, Summer 1985, pp. 265-274.

Gass, Saul I., "The Analytic Hierarchy Process," Chapter 24 of Decision Making, Models, and Algorithms (New York: John Wiley and Sons, 1985), pp. 355-397.

Goicoechea, Ambrose, Hansen, Don R., and Duckstein, Lucien, Multiobjective Decision Analysis with Engineering and Business Applications (New York: John Wiley and Sons, 1982).

Goumain, Pierre (ed.), High-Technology Workplaces: Integrating Technology, Management, and Design for Productive Work Environments (New York: Van Nostrand Reinhold, 1989).

Hogan, John D. (ed.), Dimensions of Productivity Research: Proceedings of the Conference on Productivity Research, Houston, TX, April 21-24, 1980.

Marans, Robert W. and Spreckelmeyer, Kent F., Evaluating Built Environments: A Behavioral Approach (Ann Arbor, MI: University of Michigan, 1981).

Mirvis, Philip H. and Lawler, Edward E., "Measuring the Financial Impact of Employee Attitudes," Journal of Applied Psychology, Vol. 62, No. 1, 1977, pp. 1-8.

Nelson, T.M., Nilsson, T.H., and Hopkins, G.W., "Thermal Comfort: Advantages and Deviations," ASHRAE Transactions, Vol. 93, Pt. 1, 1987, pp. 1039-1054.

"Office Lighting, Comfort and Productivity --- How the Workers Feel," Lighting Design and Application, Vol.10, No.7, July 1980, pp. 35-40.

Osgood, Robert T., Jr., "Measuring the Bottom Line Impact of Design and Facility Management on Office Workers' Satisfaction and Productivity," in IFMA '89: Excellence in Facility Management, Seattle, WA, 1989.

Page-Shipp, R.J., The Physical Working Environment and its Effect on Productivity in Offices, (Pretoria, South Africa: National Building Research Inst., 1981). 
Petersen, Stephen R., DISCOUNT--A Program for Discounting Computations in Life-Cycle Cost Analyses, NISTIR 4513 (Gaithersburg, MD: National Institute of Standards and Technology, 1991).

Rubin, Arthur and Gillette, Gary, Guideline for Work Station Design, NISTIR 89-4163 (Gaithersburg, MD: National Institute of Standards and Technology, 1989).

Rubin, Arthur, Office Design Measurements for Productivity--A Research Overview, NBSIR 873688 (Gaithersburg, MD: National Bureau of Standards, 1987).

Rubin, Arthur, Post-Occupancy Evaluation of Federal Buildings--The Portland Federal Building and Others, NISTIR 4307 (Gaithersburg, MD: National Institute of Standards and Technology, 1990).

Ruch, William A. "The Measurement of White-Collar Productivity," National Productivity Review, Autumn 1982, pp. 416-426.

Ruck, Nancy C. (ed.), Building Design and Human Performance, (New York: Van Nostrand Reinhold, 1989).

Ruegg, Rosalie T. and Marshall, Harold E., Building Economics: Theory and Practice (New York: Van Nostrand Reinhold, 1990).

Saaty, Thomas L., The Analytic Hierarchy Process: Planning. Priority Setting Resource Allocation (New York: McGraw-Hill, Inc., 1988).

Skov, Peter et al., "Influence of Indoor Climate on the Sick Building Syndrome in an Office Environment," Scandinavian Journal of Work and Environmental Health, Vol.16, No.5, October 1990, pp. 363-371.

Skov, Peter et al., "The 'Sick' Building Syndrome in the Office Environment: The Danish Town Hall Study," Environmental International, Vol. 13, No.44, 1987, pp. 339-349.

"Standard Practice for Measuring Net Benefits for Investments in Buildings and Building Systems (E 1074-91)," 1991 Annual Book of ASTM Standards, Vol. 04.07 (Philadelphia, PA: American Society for Testing and Materials, 1991), pp. 876-878.

Steelcase, Inc. and Harris \& Associates, Inc., Office Environment Index: 1989 Detailed Findings (New York, 1989).

Stout, David E., Liberatore, Matthew J., and Monahan, Thomas F., "Decision Support Software for Capital Budgeting," Management Accounting, Vol. 73, No. 1, July 1991, pp. 50-53.

Tuttle, Thomas C. and Romanowski, John J., "Assessing Performance and Productivity in WhiteCollar Organizations," National Productivity Review, Summer 1985, pp. 211-224. 
United States Environmental Protection Agency, Report to Congress on Indoor Air Quality. Volume II: Assessment and Control of Indoor Air Pollution, (Washington, DC, 1989).

Ward, Robertson, Jr., "Office Building Systems Performance and Functional Use Costs," in Building Economics, edited by Dan Ove Pedersen and Jan Soderberg (Copenhagen: International Council for Building Research Studies and Documentation, 1987), pp. 113-124.

Wareham, E. A. "Is Your Lighting Worth The Price?," American City and County, Vol. 101, No.11, November 1986, pp. 58-60.

Weber, Stephen F., Lippiatt, Barbara C., and Johnson, Katherine S., AutoMan 2.0: Decision Support Software for Automated Manufacturing Investments -- User Manual, NISTIR 4543 (Gaithersburg, MD: National Institute of Standards and Technology, 1991). [The AutoMan 2.0 software and User Manual can be obtained for $\$ 55$ plus $\$ 3$ handling from the National Technical Information Service, Springfield VA 22161, (703) 487-4650. Request PB91-506568 (5.25" diskette) or PB91-507194 (3.5" diskette)].

Wilson, Sheena and Hedge, Alan, The Office Environment Survey: A Study of Building Sickness (London: Health Promotion Research Trust, Building Use Studies, 1987).

Woods, James E., "Cost Avoidance and Productivity in Owning and Operating Buildings," Occupational Medicine: State of the Art Reviews, Vol. 4, No. 4, October-December 1989, pp. 753-770.

Zeleny, Milan, Multiple Criteria Decision Making (New York: McGraw-Hill, Inc., 1982). 


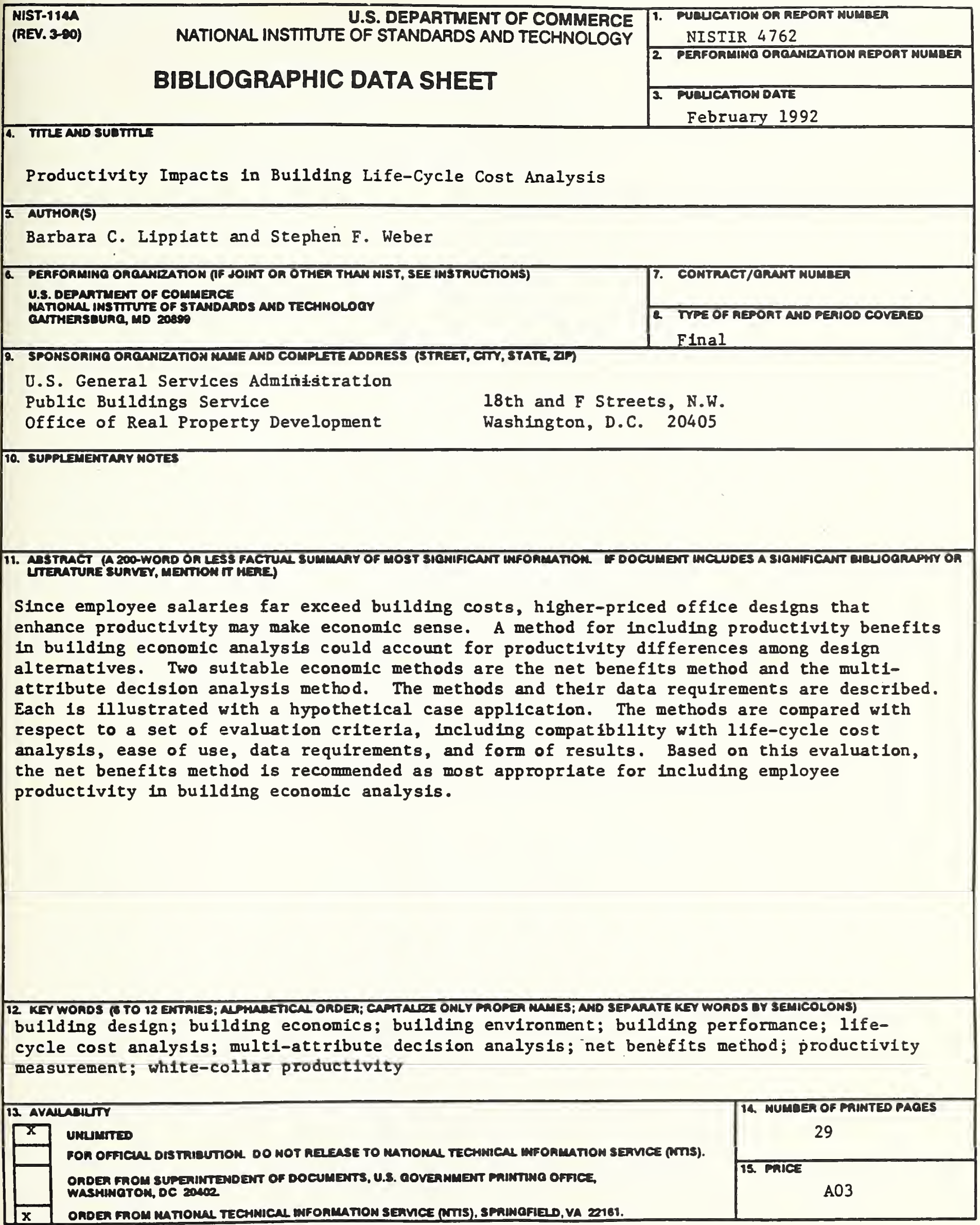

ELECTRONIC FORM 


